\title{
ARFI: from basic principles to clinical applications in diffuse chronic disease - a review
}

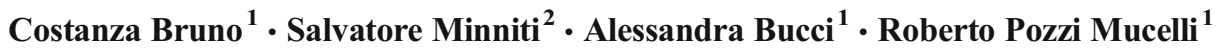

Received: 29 January 2016 / Revised: 5 July 2016 / Accepted: 19 July 2016 / Published online: 23 August 2016

(C) The Author(s) 2016. This article is published with open access at Springerlink.com

\begin{abstract}
The many factors influencing the shear wave velocity (SWV) measured with Acoustic Radiation Force Impulse (ARFI) are examined in order to define the most correct examination technique. In particular, attention is given to the information achieved by experimental models, such as phantoms and animal studies. This review targets the clinical applications of ARFI in the evaluation of chronic diffuse disease, especially of liver and kidneys. The contribution of ARFI to the clinical workout of these patients and some possible perspectives are described.
\end{abstract}

\section{Teaching Points}

- Stiffness significantly varies among normal and abnormal biological tissues.

- In clinical applications physical, geometrical, anatomical and physiological factors influence the SWV.

- Elastographic techniques can quantify fibrosis, which is directly related to stiffness.

- ARFI can be useful in chronic diffuse disease of liver and kidney.

Keywords Elasticity imaging techniques · Anisotropy ·

Fibrosis $\cdot$ Liver cirrhosis $\cdot$ Kidney diseases

*This work received no grant funding.

Costanza Bruno

costanza_bruno@libero.it; clgbruno@gmail.com

1 Department of Radiology, Verona University, P.le LA Scuro 10, 37134 Verona, Italy

2 Technomed, Verona, Italy

\section{Introduction}

Adopted from clinical practice from long ago, palpation examines the mechanical properties of target organs following the general logic shared by all modern imaging methods: it explores tissues detecting the effects determined by an external force. While conventional radiology and computed tomography extract information from the differential attenuation of X-photons due to density and to the mean atomic number in the body volume sampled, the background of palpation-based diagnosis lies in the relationship linking several diseases to the modifications of tissue stiffness that they induce. The principle of palpation has been recently applied to a series of elasticitybased modalities generally defined as "strain-imaging techniques", in which diagnostic information derives from the response of the explored tissue (closely related to its elastic properties) to forces inducing mechanical modifications. Both quasi-static (based on manual compression) and dynamic strain-imaging techniques have been developed: these latter use as a stimulus rapidly attenuating shear waves resulting from mechanical vibrations. Such vibrations can be applied either outside (like in Transient Elastography: TE) or in "internal" techniques, directly inside the body.

Acoustic Radiation Force Impulse (ARFI) is a recently developed, dynamic, internal technique that superimposes data concerning tissue elasticity to a conventional grayscale image generated by commercial ultrasound (US) scanners. In this article, the basic technological principles of the ARFI method, with emphasis on the factors that determine the results, are reported, and its current diagnostic role in diffuse disease (especially of liver and kidney) is critically reviewed. 


\section{ARFI imaging}

\section{Physical principles}

In the ARFI technique, the shear waves exciting the target tissue are generated inside a fixed-size $(1 \times 0.5 \mathrm{~cm})$ region of interest (ROI), placed at the choice of the operator on a conventional gray-scale ultrasound (US) image. In brief, focused, short-duration acoustic push pulses travelling along the main US beam [1] induce within tissues shear stresses, with modalities and intensities depending upon tissue attenuation (mainly due to absorption), acoustic frequency, and intensity of the acoustic beam [2]. In turn, the shear stresses give rise to shear waves that propagate, perpendicular to the main US beam, away from the original region of excitation (Fig. 1). In a theoretical, perfectly homogeneous and isotropic target, the speed of propagation of the shear waves is directly proportional to the density and to the shear modulus of the tissue [1], the latter being related to its elasticity. Therefore, if density does not vary, softer tissues exposed to a given radiation force move farther than stiffer tissues, and, having a lower shear modulus, take longer to reach their peak displacement (on the order of tens of microns), and recover more slowly [3].

Together with the push pulses, low-intensity tracking US beams are continuously emitted parallel to the main beam in order to monitor the tissue displacement. The tracking beams intercept the shear wave front at several predetermined locations and time intervals, which allows a series of data concerning the tissue response to be obtained, such as the time-to-peak displacement and the recovery time (Fig. 1). From these data, mainly through time-of-flight algorithms, quantitative estimates of the speed of propagation of the shear waves, and then of the tissue stiffness, are obtained [1, 4].

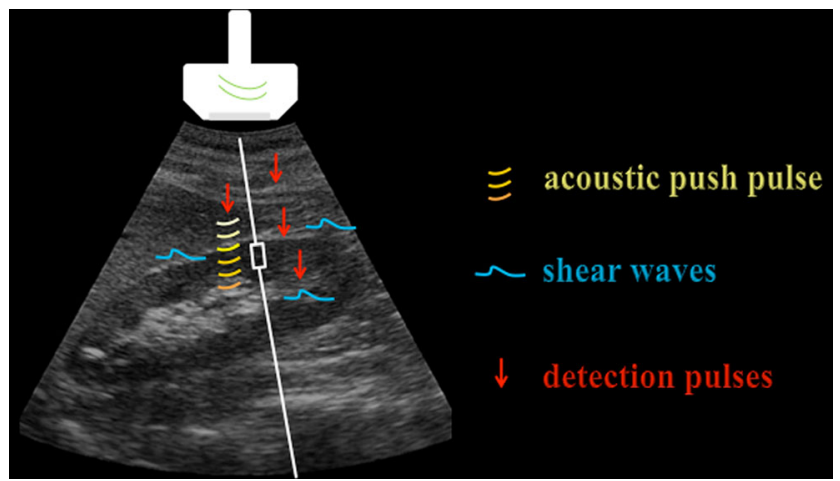

Fig. 1 Schematic representation of the ARFI technique. On a conventional gray-scale US image (oblique scan including the right kidney and the lowest portion of the right lobe of the liver), acoustic push pulses (curved lines) are generated together with the main US beam. From the push pulses originate shear waves (dashed horizontal lines) propagating perpendicular to the main US beam, which are sampled by tracking beams (arrows) parallel to the main beam. The actual distance covered by the shear waves before their attenuation is limited: the data concerning tissue response can only be achieved within a small ROI (rectangular box along the straight vertical line)
Such information can be displayed by ARFI systems as either a map reflecting spatial differences in tissue stiffness, ormore commonly-quantitatively: in most cases, the tissue elasticity is then expressed as shear wave velocity (SWV), usually measured in meters per second $(\mathrm{m} / \mathrm{s})$.

\section{Factors influencing the speed of propagation of the shear waves}

Under ideal experimental conditions (i.e. if both tissue density and all variables related to the US beam and to the generation of shear waves are constant), the elasticity of the target volume is the only determinant of the SWV values measured by ARFI (Fig. 2). In clinical applications, however, the speed at which the shear waves propagate through the medium is strongly influenced by many disturbing factors. The operator must comprehend the physical, geometrical, anatomical and
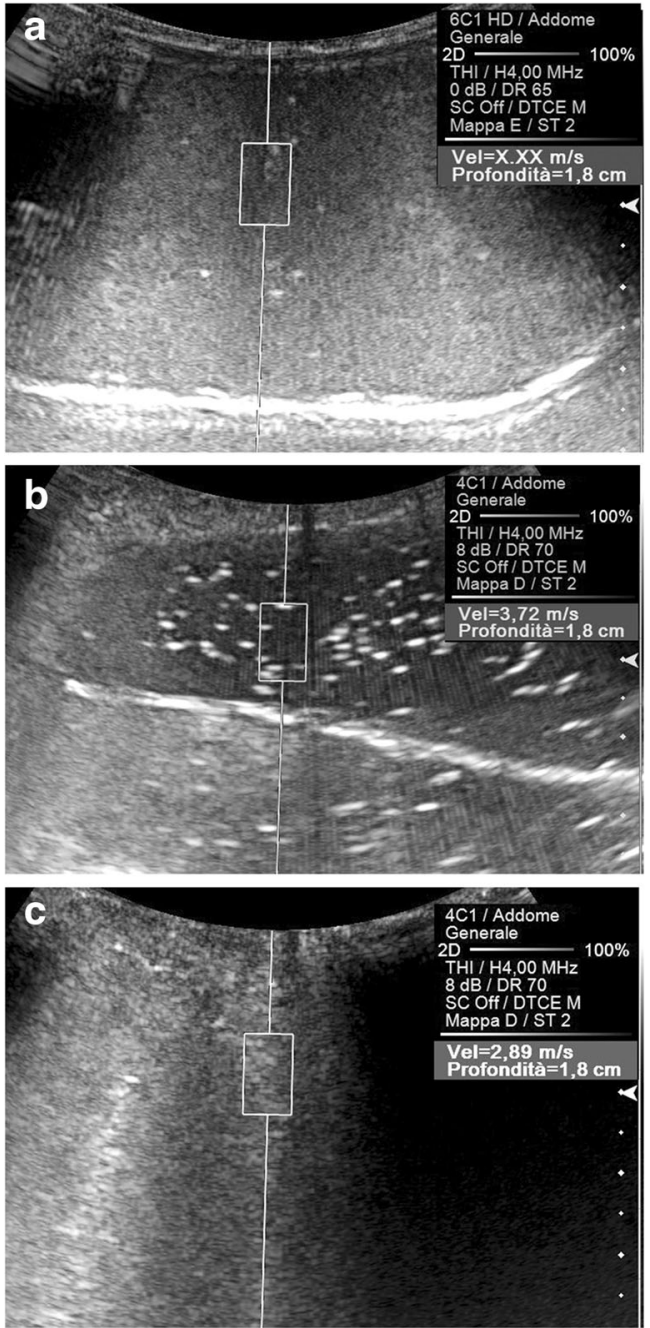

Fig. 2 Effect of the elasticity of the target on the speed of propagation of the shear waves. Shear waves do not generate (SWV not measurable: "X.XX") in pure water (a) and travel quite fast $(3.72 \mathrm{~m} / \mathrm{s})$ in oil $(\mathbf{b})$. In a water-oil emulsion (c) the SWV $(2.89 \mathrm{~m} / \mathrm{s})$ is lower than in pure oil 
physiological factors potentially capable of modifying the speed of propagation of the shear waves in order to adequately perform the ARFI examination, and thus to avoid dangerous misinterpretation of its results. In the clinical practice, the inappropriate setting of any of the following parameters gives rise to unreliable SWV measurements; moreover, changes of such parameters through follow-up studies may generate variations in the values obtained that could be erroneously attributed to changes in the actual stiffness of the target organs.

- Physical factors affecting the propagation of the shear waves are both intrinsic to the main US beam and extrinsic. The most relevant intrinsic factor is the wavelength: if lower transmitting frequencies are used, lower-frequency pulses are generated, which in turn exert greater acoustic pressure, resulting in faster-travelling shear waves. Exploring both experimental phantoms and normal tissues in vivo with different US frequencies [5], a slight but statistically significant difference in the apparent stiffness was obtained (Fig. 3).

Among the physical factors extrinsic to the US beam, two variables have to be considered. The stronger the compression manually exerted on the transducer, the higher the
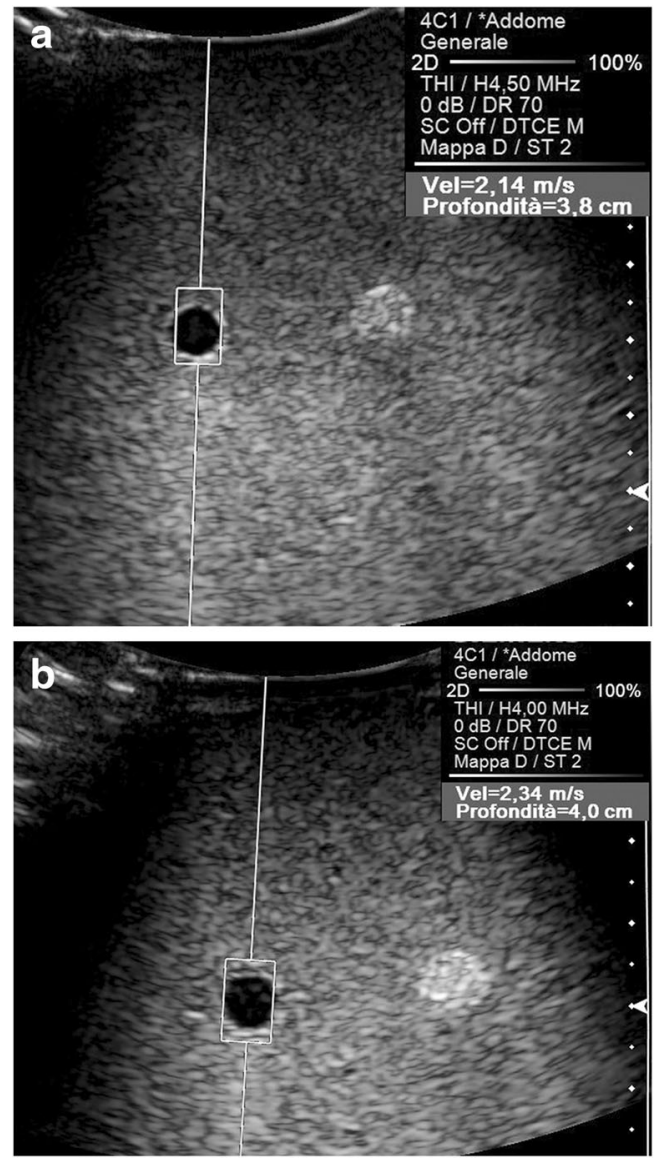

Fig. 3 Effect of the wavelength on the speed of propagation of the shear waves. A lower SWV value $(2.14$ vs. $2.34 \mathrm{~m} / \mathrm{s})$ is attributed to a given target (a sphere of gel included into a phantom) using a $4.5 \mathrm{MHz}$ (a) compared to a $4.0 \mathrm{MHz}(\mathbf{b})$ transmitting frequency tissue density becomes, which increases the speed of propagation of the shear waves (Fig. 4); in an experimental study in which the force applied on the probe was exactly quantified, the SWV values measured in kidney allografts were significantly affected by the degree of compression [6]. In addition, the speed of propagation of the shear waves decreases at greater source-to-target distances, paralleling the progressive attenuation of the pulses generating the shear waves as they travel within tissues (Fig. 5). Significantly lower SWV values were obtained in the deep than in the superficial portion of the right lobe of the liver in healthy volunteers [5,7], and in the deeper parts of homogeneous phantoms in experimental studies [5, 8]. It is, however, possible that the apparent lower elasticity of deeper targets results from the combined effect of the greater distance from the transducer and of the weaker compression that objects more deeply sited undergo.

- Geometry too plays a role in determining the speed of propagation of the shear waves. The more parallel the
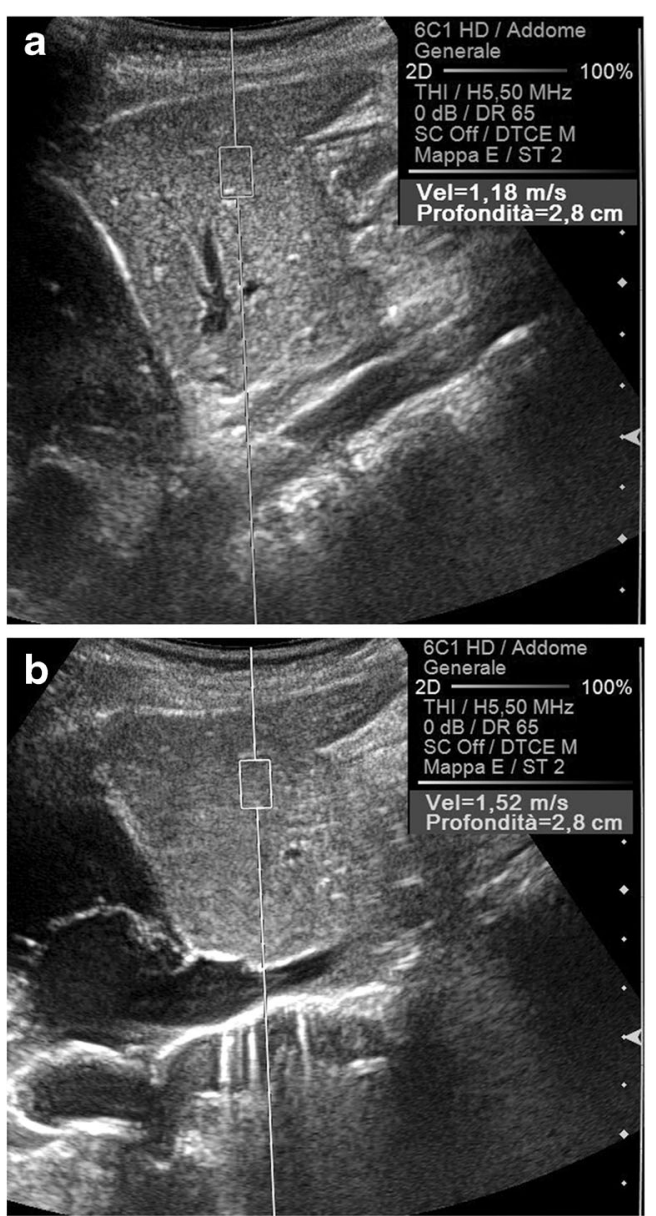

Fig. 4 Effect of the compression on the speed of propagation of the shear waves. Longitudinal US scans on the left lobe of the liver in a healthy subject. A lower SWV value (1.18 vs. $1.52 \mathrm{~m} / \mathrm{s})$ is measured, exerting on the transducer a mild (a) rather than a strong (b) manual compression 

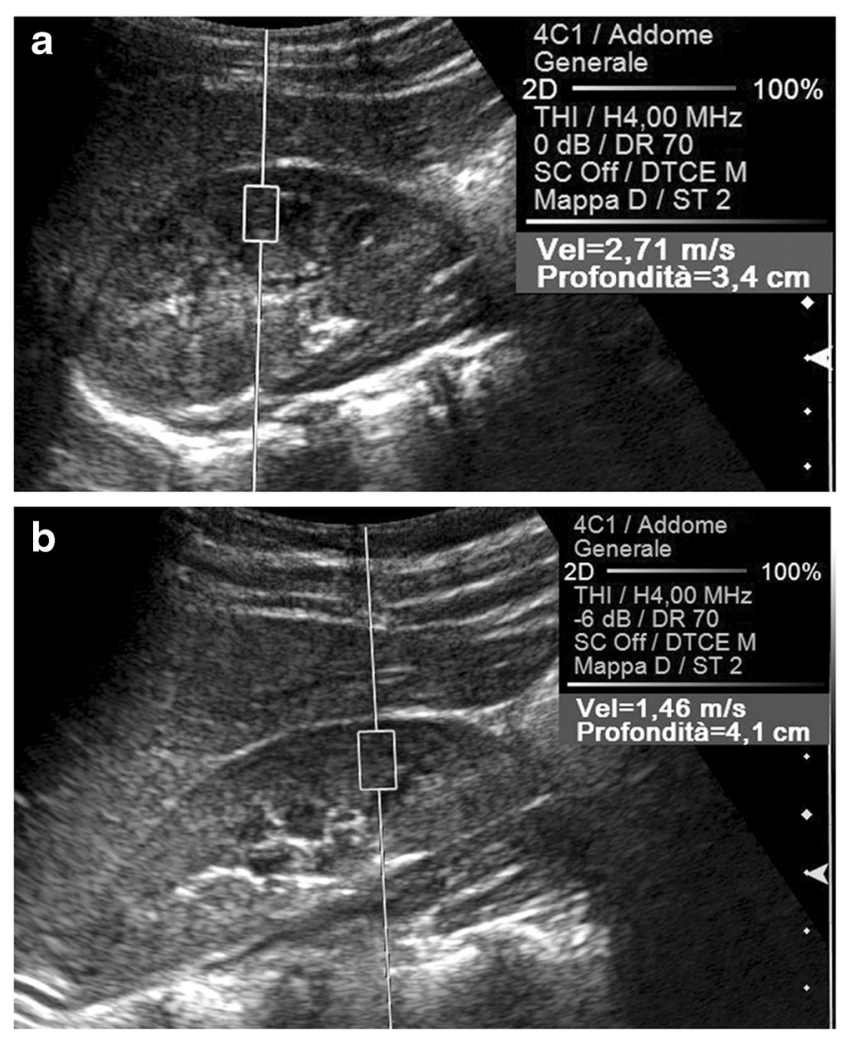

Fig. 5 Effect of the source-to-target distance on the speed of propagation of the shear waves. Oblique US scans on the right kidney in a healthy, thin subject. A higher SWV value ( 2.71 vs. $1.46 \mathrm{~m} / \mathrm{s}$ ) is measured in the renal cortex using a posterior approach (a), in which the kidney is closer to the skin surface, compared to using an anterior approach (b)

ROI is oriented to the main US beam, the higher the SWV results are in a given target (Fig. 6), presumably because of the greater number of interfaces impeding the transmission of the shear waves at increasing obliquities.

- At least two categories of anatomical factors strongly influence the propagation of the shear waves. As a first consideration, within some organs - composed of macroscopic portions each having its own structure - uneven obstacles are opposed to the progression of the shear waves, similarly to the differences in the acoustic impedance regulating the transmission of US beams. Shear waves are expected to meet more architectural disturbances in the sinus than in the cortex of normal kidneys, which is the likely basis of the lower sinusal SWV values (Fig. 7).

The most important anatomical factor, however, is anisotropy, which reflects the direction dependence of certain properties that some organs demonstrate (Fig. 8). Most of the current knowledge about the effects of anisotropy on the transmission of shear waves derives from an experimental work by Gennisson on an animal model using supersonic shear waves imaging [9], a variant of the ARFI technique in which the pulses generating the shear waves move more quickly in tissues.
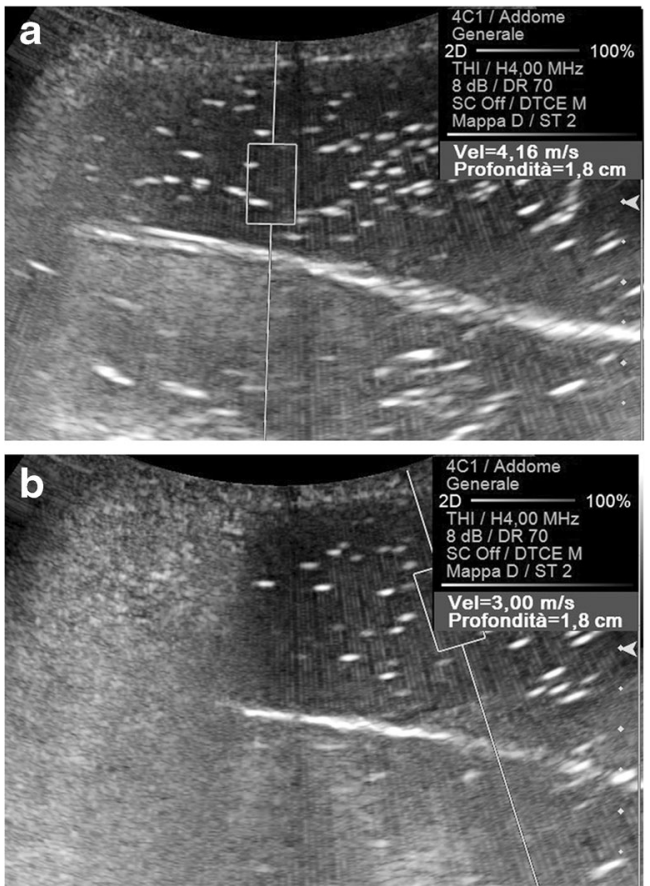

Fig. 6 Effect of the orientation of the ROI on the speed of propagation of the shear waves. A higher SWV value ( $4.16 \mathrm{vs.} 3.00 \mathrm{~m} / \mathrm{s})$ is attributed to a given target (oil) with a ROI parallel (a) rather than oblique (b) to the main US beam

A marked anisotropy is normally present in the renal medulla, where - within a given renal segment-Henle loops and vasa recta are parallel to each other, all being oriented from the capsule to the papilla (Fig. 9); the same does not happen in the cortex, mostly occupied by glomeruli and by convoluted proximal and distal tubules, with all of these structures approximately spherical in shape. If the main US beam is sent parallel to a renal segment, it generates shear waves travelling perpendicular to the spatially oriented medullary structures, and then encountering multiple interfaces that decrease their speed of propagation, which results in apparently lower elasticity values (Fig. 9). On the contrary, a main US beam perpendicular to Henle loops and vasa recta gives rise to shear waves parallel to such structures and then hindered by much fewer interfaces (Fig. 9), with consequent higher apparent elasticity [9]. In the model of Gennisson, the mean variation of the apparent shear modulus due to the medullary anisotropy was as high as $31.8 \%$ [9], which is consistent with the $40 \%$ fractional anisotropy demonstrated in the renal medulla with diffusion-Magnetic Resonance (MR) [10]. Moreover, a significantly higher speed of shear waves travelling parallel than perpendicular to spatially oriented anatomical structures was observed in muscles [11], in the myocardium [12], and in the brain [13].

- Like anisotropy, the physiological factors affecting the propagation of the shear waves are especially relevant in 

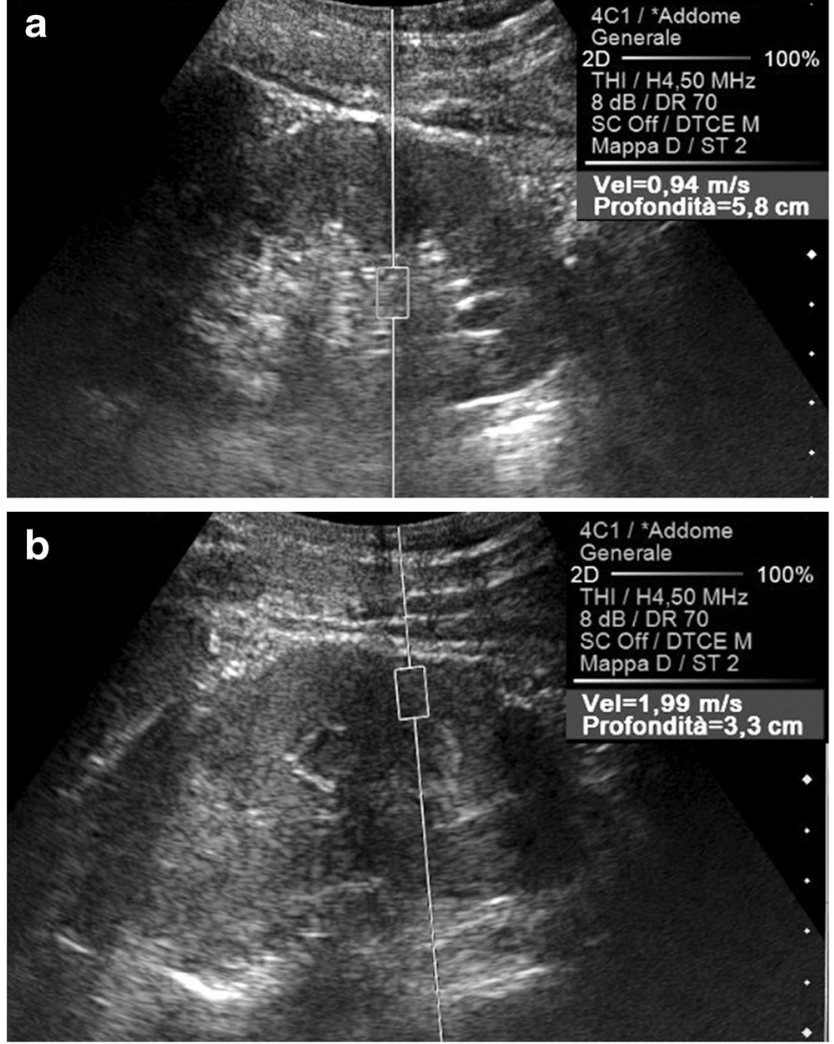

Fig. 7 Effect of anatomy on the speed of propagation of the shear waves. Oblique US scans on the right kidney in a healthy subject. A lower SWV value $(0.94$ vs. $1.99 \mathrm{~m} / \mathrm{s})$ is measured in the renal sinus (a) compared to in the parenchyma (b)

the kidneys. In the above-mentioned model [9], a linear relationship of the SWV values to the pressure within the excretory system and to the vascular pressure was demonstrated. In particular, the apparent renal elasticity decreased after ligation of the renal artery (which is in accordance with the results observed with MR-elastography during experimentally induced ischemia) [14], and increased after ligation of the renal vein [9]. This latter behaviour parallels the observations made in otherwise normal organs in which a pressure overload arises as a

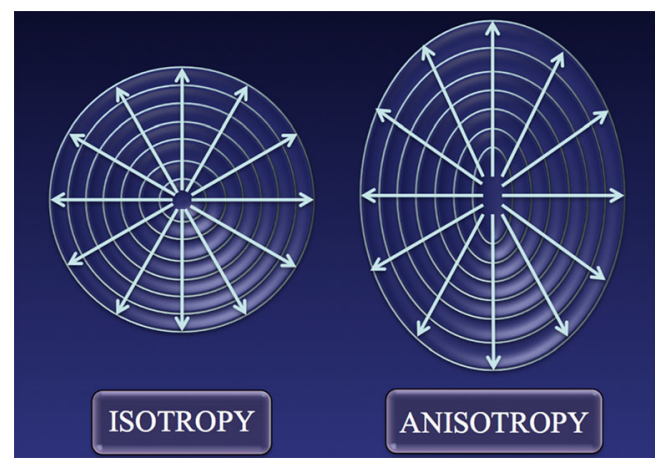

Fig. 8 Schematic representation of an isotropic and an anisotropic object: in the latter, properties vary in the different planes. The term comes from

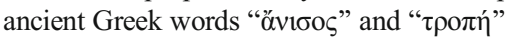
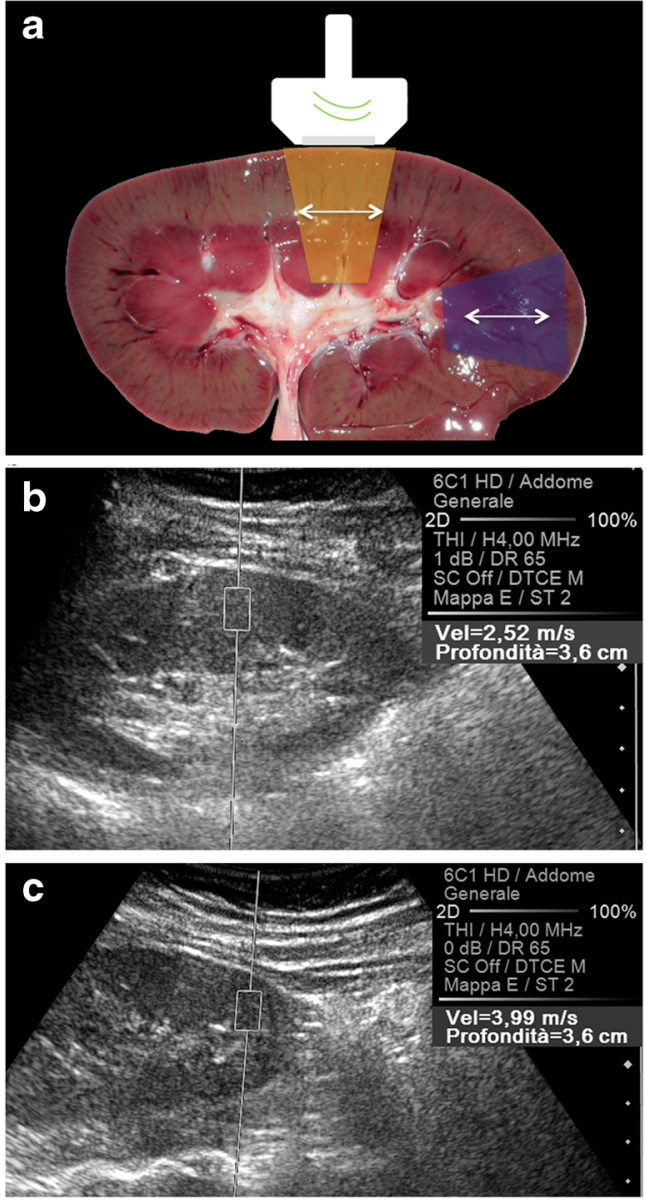

Fig. 9 Effect of anisotropy on the speed of propagation of the shear waves. When the axis of the main US beam is parallel to the orientation of the vasa recta and Henle loops (orange box in a), the shear waves travel perpendicular to these structures and then move slowly $(2.52 \mathrm{~m} / \mathrm{s}$ in b). In the opposite condition (blue box in a), the SWV is higher $(3.99 \mathrm{~m} / \mathrm{s}$ in c)

consequence of an obstacle to the venous outflow, such as in the liver of patients with right heart failure [15] and in the spleen in case of portal hypertension, both in animal models [16] and in vivo [17-19].

\section{Clinical applications of ARFI}

\section{Safety, feasibility and reproducibility}

Prior to the validation of its diagnostic performances, ARFI had to be demonstrated to be a safe technique, quick and easy to perform and providing reproducible results in different settings.

The range of energy of the acoustic beams is similar in common ARFI practice (mechanical index: 1.3 to 1.6 ) and in conventional gray-scale US. At these levels, the absorption of acoustic energy in biological tissue is expected - besides acoustic radiation force - to generate heat, the amount of 
which is mainly influenced by transmit frequency and pulse duration. For an individual excitation, the temperature rise is very limited, ranging from 0.02 to $0.2{ }^{\circ} \mathrm{C}$ : it takes less energy to displace tissue several microns than to raise its temperature by a fraction of a degree Celsius [1]. Moreover, the thermal safety of ARFI has been experimentally confirmed with both in vitro measurements and finite-element method models [20].

Although radiation forces generated by US beams having intensities and frequencies commonly used in conventional US can cause tissue displacement until a maximum depth shallower than the corresponding B-mode imaging depth [1], from the beginning, ARFI proved to be capable of exploring abdominal targets at a reasonable depth from the skin surface [20], which prompted to its introduction in clinical practice.

The disturbing effect of motion artifacts, caused by both transducer and underlying physiological movements, is easily removed by motion filters; furthermore, multiple reference tracking beams are emitted before push pulses are generated in order to sample baseline motion [1].

As a subsequent historical step in the validation of ARFI technique, images were achieved with a good correspondence to conventional US images, both on cancers after their surgical removal and on normal organs in vivo [20], especially in the abdomen (liver, kidneys, pancreas, spleen), but also in the thyroid and in the testes [21, 22]. However, high standard deviations in the SWV values measured were obtained in these pioneer studies, particularly in the kidneys [21], which limited the enthusiasm for ARFI and inspired several researchers to identify the factors affecting the speed of the propagation of the shear waves. With improving experience of the operators and technical performance of the instruments, however, higher repeatability and reproducibility rates have been achieved, reaching a near-perfect interoperator agreement (intra-class correlation coefficient: $0.99-1.00$ ) in a recent study based on phantoms [8].

With regard to the evaluation of normal and abnormal kidneys, however, a widespread acceptance of the reproducibility of the results of ARFI has not been achieved to date [6, 21, 23-26]. While some authors remain skeptical [6], in the current opinion, ARFI is considered a valuable tool in the exploration of the kidneys, provided that a correct technique is adopted: their anatomical and physiological complexity makes the kidneys more exposed than other organs to most of the factors influencing the propagation of the shear waves. In particular, applying a constant force on the transducer contributes to reducing the variability of the SWV measures, especially in renal allografts, more sensitive than native kidneys to uneven compression because of their more superficial location. A clear identification of the renal segments explored and of their orientation with regard to the US and the shear wave beam is mandatory, due to anisotropy (Fig. 9), for a correct interpretation of the SWV values measured [9, 25]. Urinary obstruction must be ruled out before attributing an increased elasticity to tissue disease [9], and SWV values should be measured soon after micturition [25], especially in transplanted kidneys, where the effect of bladder distension on the pressure in the pyelocaliceal system is magnified by the shortness and the denervation of the ureter [27]. Finally, placing the ROI entirely in the outer renal cortex allows exclusion of the disturbing effects on SWV measurements of both anisotropy (originating in the medulla) and urinary and vascular pressure, the former localized in the calices and the latter in the great medullary vessels [25].

\section{Evaluation of chronic diffuse disease}

\section{Liver}

Chronic liver disease is very common in clinical practice: its more frequent causes are infection with hepatitis viruses $\mathrm{B}$ and $\mathrm{C}$, ethanol abuse, non-alcoholic steatohepatitis, autoimmune hepatitis, and primary biliary cirrhosis. In these patients, a precise estimation of liver fibrosis is crucial both for the planning of treatment (especially in viral hepatitis) and for the assessment of outcome, the degree of fibrosis representing the strongest prognostic indicator [28-30]. On a five-point scale, treatment is commonly considered necessary for levels of fibrosis of 2 ("significant") or above; grade-3 fibrosis is "severe" and cirrhosis corresponds to grade 4 , while $\mathrm{F}=0$ and $\mathrm{F}=1$ respectively indicate an absent and a "mild" fibrosis. Liver biopsy is still considered the gold standard in the evaluation of fibrosis [28, 31]; it can also reveal fatty infiltration or specific markers for some diseases, such as Mallory bodies in alcoholic steatohepatitis [30]. However, the average bioptic specimen only represents $1 / 50,000$ of the total liver volume, its dimension and content of portal tracts widely varying, which may constitute a major diagnostic limitation considering the uneven distribution of fibrosis throughout the liver [30]. Moreover, liver biopsy is an invasive procedure: in up to $6 \%$ of cases, complications occur [32], which in 0.04 $0.11 \%$ may be life-threatening [30].

On the assumption that a direct proportionality exists between the degree of fibrosis and liver stiffness, both quasistatic and dynamic shear-wave elastographic techniques have been widely used, aimed at a quick, non-invasive and reliable quantification of fibrosis. Among the latter group, TE was introduced in clinical practice more than a decade ago. Several meta-analyses assessed that the measurement of liver stiffness by means of TE, in patients with chronic hepatopathies, significantly correlates with the histological degree of fibrosis [33-35], allowing to reliably identify the stages $\mathrm{F} \geq 2$.

For historical reasons, therefore, this clinical application of ARFI has been initially validated through a comparison with the already known diagnostic performances of TE, and in no 
correlative study were significant differences demonstrated between the accuracies of ARFI and TE [33, 36-42]. ARFI, however, had a significantly lower rate of unsuccessful measurements than did TE [38, 43]: unlike TE, ARFI takes advantage of a conventional US image to choose the positioning of the ROI in both planes, and is therefore less sensitive to the presence of ascites and to obesity. Moreover, ARFI performed better than a scoring system based on the visual assessment of conventional US images by experienced radiologists in correlation with Child-Pugh scores and liver function tests, and better than aspartate-to-platelet ratio in predicting severe fibrosis and cirrhosis in patients with alcoholic liver disease [44]. In experimental fibrosis induced in a rat liver model, ARFI proved very reliable in the staging of fibrosis [45].

For the assessment of liver fibrosis (Fig. 10), ARFI scanning is usually performed in the supine position, applying minimal scanning pressure, while the patient is asked to stop breathing [30]; no significant variations were, however, demonstrated measuring the SWV values with or without deep inspiration [7, 15]. An intercostal approach in the right liver lobe is preferred, since in the left lobe, cardiac pulsation causes excessive tissue motion, potentially disrupting shear waves; in addition, measurements in the left lobe tend to be taken closer to the hepatic capsule, where tissue is often more fibrous than in deeper portions $[46,47]$. The mean body mass index is known to interfere with the reliability of the procedure [48-51], while equivocal data have been reported concerning possible effects on the SWV values of patient's age and gender, food intake, patient's position, and shape of the transducer (convex versus linear probe [5, 7, 15, 49, 50, 52]. Moreover, steatosis and acute inflammation (both likely to occur in chronic liver disease) may interfere with hepatic stiffness [51, 53-55]. The best cutoff points for SWV values emerging from the meta-analyses are $1.31 \mathrm{~m} / \mathrm{s}$ for the fibrosis stages $\geq 2$ and 1.8 for $\mathrm{F}=4$ [38]; according to some authors [44, 54], these figures should be corrected according to serum alanine aminotransferase levels. As for its diagnostic performances, many published data report good accuracy of ARFI in chronic viral and alcoholic liver disease [33, 36-39, 48]. In the diagnosis of $F \geq 2$, ARFI showed $74 \%$ summary sensitivity and $83 \%$ summary specificity, both reaching $87 \%$ in the diagnosis of $\mathrm{F}=4$ [38]; the area under receiver operating curve (AUROC) values were 0.84 for $\mathrm{F} \geq 2,0.89$ for $\mathrm{F} \geq 3$ and 0.91 for $\mathrm{F}=4$ [48]. In a retrospective multicenter study, the correlation between SWV values and histological fibrosis was highly significant $(p<0.0001)$, even if a large overlap of values occurred in the stages of 2 or below, with only $F \geq 2$ and cirrhosis being excluded with great certainty [39]. Better results were obtained in European than in Asian patients [39, $56]$, and in patients infected with hepatitis virus $C$ than in those with virus B [56-58].

As for chronic liver disease due to less common etiologies, ARFI proved reliable in differentiating significant from non-
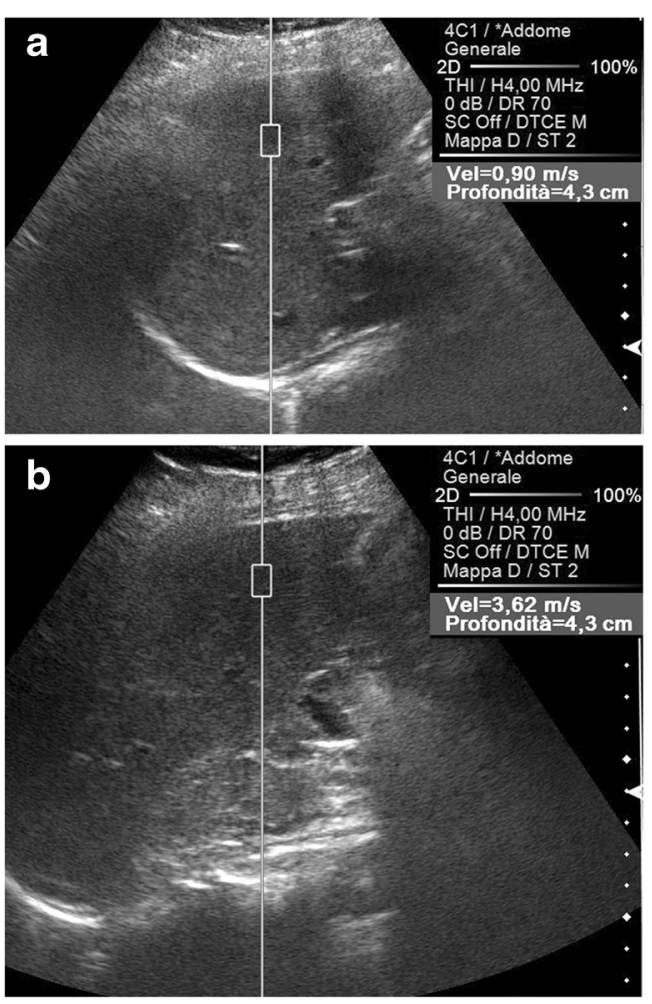

Fig. 10 ARFI evaluation of liver. Transversal US scans on the right lobe of the liver in two different patients with chronic liver disease due to hepatitis virus C. The SWV value is lower $(0.90$ vs. $3.62 \mathrm{~m} / \mathrm{s})$ in a $41-$ year-old man with fibrosis stage 1 at histology (a) than in a 51-year-old man with fibrosis stage 3 (b)

significant steatosis in children with biliary atresia [59] and in adult patients with autoimmune hepatitis [60] and with primary biliary cirrhosis [61]. In patients with non-alcoholic fatty liver disease, in whom an increased risk of developing hepatocellular carcinoma exists only if advanced fibrosis is present, a meta-analysis reported summary sensitivity of $80.2 \%$ and specificity of $85.2 \%$ in the ARFI-based detection of significant fibrosis [62]. Moreover, a reliable differentiation between significant and non-significant fibrosis was obtained in liver allografts in patients infected with hepatitis virus C [63].

The accuracy of ARFI in the prediction of complications of chronic liver disease is more controversial. Although in most cases the risk of bleeding from esophageal varices is low, the current guidelines recommend endoscopy in all patients, in order to identify those who would benefit from prophylactic treatment [64], which led some authors to try a non-invasive measurement of the portal vein pressure. An elevation of liver and spleen elasticity was demonstrated with MR elastography in an animal model of portal hypertension, preceding the development of liver fibrosis [16]. In patients with chronic liver disease, a correlation between liver SWV values and portal hypertension was found by some authors $[65,66]$ and denied by others $[17,30]$. In some studies, the absolute spleen stiffness $[17,18]$ or its ratio to liver stiffness [19] correlated well with the portal vein pressure (Fig. 11). Hepatic SWV values 
resulted in significantly higher decompensated liver cirrhosis, whereas no significant relationship was demonstrated between hepatic SWV and the risk of occurrence of hepatocellular carcinoma [30].

\section{Kidney}

An extension of the excellent results obtained by ARFI in the liver to the evaluation of kidneys could be foreseen on the basis that a hypercellular, high-grade interstitial fibrosis leading to a progressive loss of functioning nephrons is the common final histological pathway of chronic kidney disease, whatever its cause [67], and also developments in renal allograft dysfunction. The utility for a timely diagnosis of chronic kidney disease of both morphological US parameters (such as renal size, cortical thickness, and pelvis diameter) and of the arterial resistive index measured with Doppler US is doubtful $[24,68]$, which makes renal biopsy often necessary. Moreover, scintigraphy with dimercaptosuccinic acid labelled with technetium-99 m $\left({ }^{99 \mathrm{~m}} \mathrm{Tc}-\mathrm{DMSA}\right)$, a procedure associated with a certain amount of radiation exposure, is recommended by the current guidelines in the evaluation of several pediatric forms, especially in European countries [67, 69]. A pilot study [70] showed that renal parenchymal stiffness measured with TE reflected interstitial fibrosis in allografts, and a good correlation of the cortical stiffness to the global histological

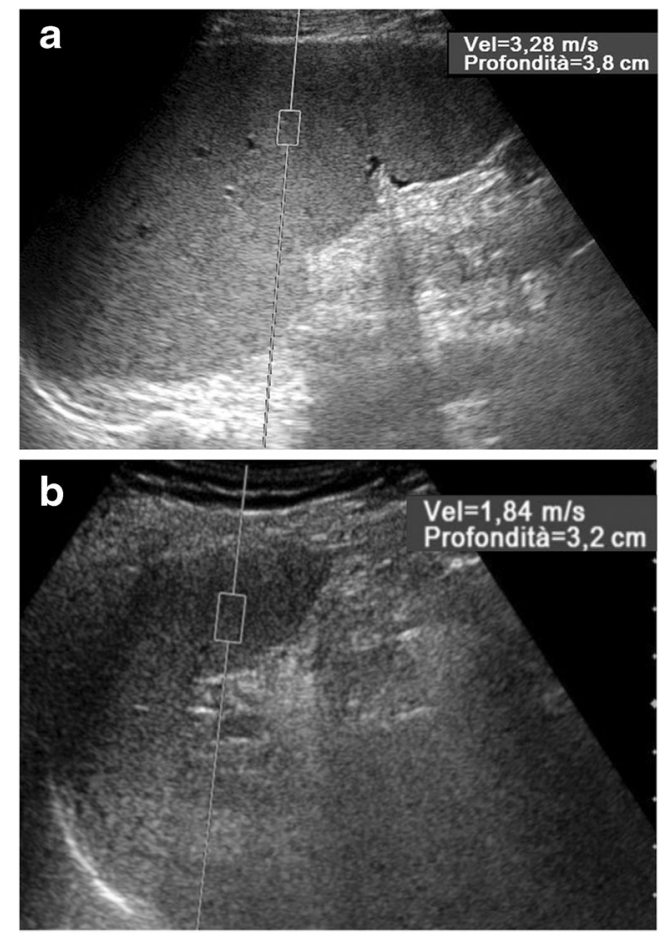

Fig. 11 ARFI evaluation of the spleen in patients with alcoholic liver cirrhosis. Longitudinal US scans. The SWV value is lower (1.84 vs. $3.28 \mathrm{~m} / \mathrm{s}$ ) in a 54-year-old man with Child-Pugh score A (a) than in a 51-year-old man with Child-Pugh score C (b), with severe portal hypertension and recurrent variceal bleeding deterioration of transplanted kidneys emerged in a study in which supersonic shear wave imaging was used [71].

However, uneven results have been reported concerning the reliability of ARFI in the evaluation of renal allografts. According to Syversveen [6], ARFI can not detect allograft fibrosis, while in another study, a significant increase in SWV values was observed in renal transplants with acute rejection, although not in other pathologies [24]. A significant correlation of SWV values with the estimated glomerular filtration rate of transplanted kidneys was observed by a different group, with $72 \%$ sensitivity and $86.5 \%$ specificity in the diagnosis of allograft dysfunction [72]. In a study in which kidney allografts examined with ARFI underwent biopsy, SWV values did not correlate with interstitial fibrosis and tubular atrophy. However, renal stiffness increased with time after transplantation, especially in the cases of a low kidney weight to body weight ratio, in which a greater amount of arterial blood is conveyed through glomeruli [73]. This result is consistent with Brenner's hypothesis that hyperfiltration that anatomically or functionally single kidneys undergo (i.e. in patients with unilateral renal agenesis, transplantation, or severe impairment of one kidney) causes damage with subsequent sclerotic changes [74].

In chronic kidney disease of the adult, one author [75] did not obtain a significant relationship of SWV values to the stage of disease and to biochemical indicators of fibrosis. One group reported a direct correlation of renal stiffness to the histological degree of fibrosis, yielding $86 \%$ sensitivity and $83 \%$ specificity with a cutoff value of $1.67 \mathrm{~m} / \mathrm{s} \mathrm{[76].} \mathrm{In}$ some studies, on the other hand, SWV values decreased concurrently with a decline in the estimated glomerular filtration rate $[77,78]$ and with the progression of histological damage. These results led to the hypothesis [78] that in severe chronic kidney disease, the diminution of renal blood flow due to nephroangiosclerosis may affect the SWV values more than tissue fibrosis does: this might be in accordance with the decrease in kidney elasticity measured with supersonic shear wave imaging in the animal model of Gennisson after ligation of the renal artery [9].

As for the pediatric population, in one study in which children younger than 2 years with pelvis dilation were examined, SWV values were significantly higher than in normal controls only when high-grade hydronephrosis was present [79]. In our experience [25], ARFI values were significantly higher than normal in children aged 8-16 years with persistent chronic kidney disease caused by a vesicoureteral reflux successfully treated at early age. The highest SWV values were found in patients whose reflux had been secondary to obstruction, in whom both retrograde urinary flow and abnormal intrarenal pressure had contributed to the initial renal damage. Moreover, we observed significantly higher stiffness in the seemingly normal kidneys contralateral to the affected kidney in children with unilateral disease than in the absolutely normal kidneys of healthy subjects 
(Fig. 12). The abnormal SWV values measured in kidneys contralateral to the affected ones may reflect the presence of lowgrade fibrosis, which is likely due to hyperfiltration damage in functionally single kidneys [74].

\section{Pancreas}

In acute pancreatitis, SWV values are reported to be significantly higher than in normal pancreas. One group obtained $97 \%$ sensitivity and $93 \%$ specificity in differentiating patients with acute pancreatitis from both normal subjects and patients with chronic pancreatitis using a $2.2 \mathrm{~m} / \mathrm{s} \mathrm{SWV}$ cutoff value [80]; in another study, with $1.63 \mathrm{~m} / \mathrm{s}$ cutoff, $100 \%$ sensitivity and $98 \%$ specificity were achieved [81]. In both papers, ARFI allowed identification of focal acute pancreatitis; moreover, a progressive SWV decrease in follow-up exams has been associated with recovery, whereas focal zones of low SWV values during the acute phase reflected areas of necrosis [80].

In one study, SWV values were significantly higher in patients with chronic pancreatitis than in healthy volunteers (Fig. 13): the sensitivity, specificity, PPV, and NPV were 75,
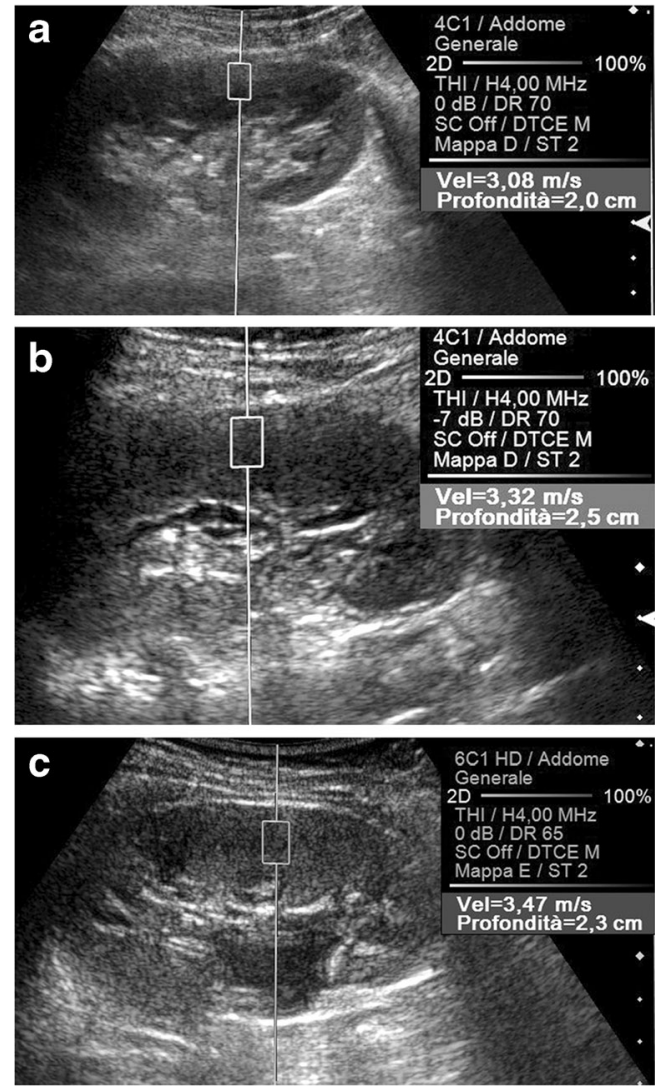

Fig. 12 ARFI evaluation of kidney. Oblique US scans on the left kidney of three different 12-year-old boys. The cortical SWV value is lower (3.08 vs. $3.47 \mathrm{~m} / \mathrm{s}$ ) in a healthy control (a) than in a boy with chronic kidney disease due to vesicoureteral reflux (c) treated at younger age. Intermediate SWV values $(3.32 \mathrm{~m} / \mathrm{s})$ are measured in the apparently normal left kidney (b) of a boy with chronic contralateral disease
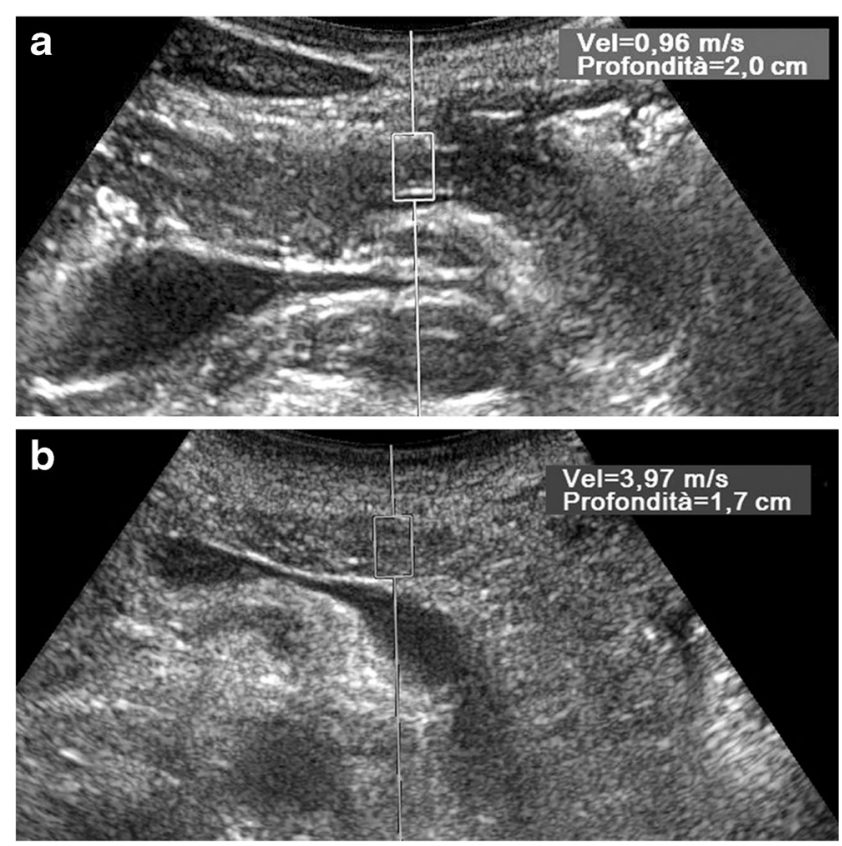

Fig. 13 ARFI evaluation of the pancreas. Axial US scans with ROI placed in the pancreatic body. The SWV value is much lower (0.96 vs. $3.97 \mathrm{~m} / \mathrm{s}$ ) in a healthy 38 -year-old man (a) than in a 48-year-old man (b) with severe chronic alcoholic non-obstructive pancreatitis

72,69 , and $78 \%$, respectively [82]. However, no significant SWV differences were detected between normal subjects and patients with chronic pancreatitis in one paper concerning acute pancreatitis [80].

Few other studies regarding the ARFI evaluation of diffuse pancreatic disease can be found. In patients with cystic fibrosis, SWV values were lower when pancreatic insufficiency existed [83]. A higher incidence of post-operative pancreatic fibrosis was demonstrated in patients whose SWV values before pancreatic resection were lower [84].

\section{Thyroid}

When the stiffness of surgical thyroid specimens was measured, a significant direct relationship of SWV values to the histological degree of fibrosis (regardless of the underlying disease) emerged [85]. As a consequence, in normal thyroids lower SWV values (mean: 1.63 to $2.00 \mathrm{~m} / \mathrm{s}$ ) were observed than in chronic autoimmune thyroiditis (2.43-2.56), yielding $62-77 \%$ sensitivity and $71-79 \%$ specificity $[86,87]$. A similar difference was demonstrated between normal thyroids and Basedow-Graves' disease [87].

\section{Conclusions}

ARFI-based quantification of tissue stiffness is a non-invasive, cheap, safe and quick imaging tool potentially capable of improving the accuracy of US examinations. ARFI reliably 
quantifies the degree of fibrosis in chronic liver disease, contributing to treatment planning and prognosis assessment, and can probably help in the staging of diffuse chronic disease of other organs, especially the kidneys. Given the high number of factors significantly influencing the measurements, the importance of a rigorous, target-tailored examination technique is critical in order to obtain reliable results.

Open Access This article is distributed under the terms of the Creative Commons Attribution 4.0 International License (http:// creativecommons.org/licenses/by/4.0/), which permits unrestricted use, distribution, and reproduction in any medium, provided you give appropriate credit to the original author(s) and the source, provide a link to the Creative Commons license, and indicate if changes were made.

\section{References}

1. Nightingale KR (2011) Acoustic radiation force impulse (ARFI) imaging: a review. Curr Med Imaging Rev 7(4):328-339

2. Nyborg WL (1965) Acoustic streaming. In: Mason WP (ed) Physical acoustics. Academic Press Inc, New York, pp 265-331

3. Palmeri ML, Sharma AC, Bouchard RR, Nightingale RW, Nightingale KR (2005) A finite-element method model of soft tissue response to impulsive acoustic radiation force. IEEE Trans Ultrason Ferroelectr Freq Control 52(10):1699-1712

4. Sarvazyan AP, Rudenko OV, Swanson SD, Fowlkes JB, Emelianov SY (1998) Shear wave elasticity imaging: a new ultrasonic technology of medical diagnostics. Ultrasound Med Biol 24(9):1419-1435

5. Chang S, Kim MJ, Kim J, Lee MJ (2013) Variability of shear wave velocity using different frequencies in acoustic radiation force impulse (ARFI) elastography: a phantom and normal liver study. Ultraschall Med 34(3):260-265. doi:10.1055/s-0032-1313008

6. Syversveen T, Midtvedt K, Berstad AE, Brabrand K, Strøm EH, Abildgaard A (2012) Tissue elasticity estimated by acoustic radiation force impulse quantification depends on the applied transducer force: an experimental study in kidney transplant patients. Eur Radiol 22(10):2130-2137. doi:10.1007/s00330-012-2476-4

7. Kaminuma C, Tsushima Y, Matsumoto N, Kurabayashi T, Taketomi-Takahashi A, Endo K (2011) Reliable measurement procedure of virtual touch tissue quantification with acoustic radiation force impulse imaging. J Ultrasound Med 30(6):745-751

8. Dillman JR, Chen S, Davenport MS et al (2015) Superficial ultrasound shear wave speed measurements in soft and hard elasticity phantoms: repeatability and reproducibility using two ultrasound systems. Pediatr Radiol 45(3):376-385. doi:10.1007/s00247-014-3150-6

9. Gennisson JL, Grenier N, Combe C, Tanter M (2012) Supersonic shear wave elastography of in vivo pig kidney: influence of blood pressure, urinary pressure and tissue anisotropy. Ultrasound Med Biol 38(9):1559-1567. doi:10.1016/j.ultrasmedbio.2012.04.013

10. Ries M, Jones RA, Basseau F, Moonen CT, Grenier N (2001) Diffusion tensor MRI of the human kidney. J Magn Reson Imaging 14(1):42-49

11. Gennisson JL, Deffieux T, Macé E, Montaldo G, Fink M, Tanter M (2010) Viscoelastic and anisotropic mechanical properties of in vivo muscle tissue assessed by supersonic shear imaging. Ultrasound Med Biol 36(5):789-801. doi:10.1016/j.ultrasmedbio.2010.02.013

12. Lee WN, Pernot M, Couade M et al (2012) Mapping myocardial fiber orientation using echocardiography-based shear wave imaging. IEEE Trans Med Imaging 31(3):554-562. doi:10.1109/TMI.2011.2172690
13. Macé E, Cohen I, Montaldo G, Miles R, Fink M, Tanter M (2011) In vivo mapping of brain elasticity in small animals using shear wave imaging. IEEE Trans Med Imaging 30(3):550-558. doi:10.1109/TMI.2010.2079940

14. Warner L, Yin M, Glaser K et al (2011) Noninvasive in vivo assessment of renal tissue elasticity during graded renal ischemia using MR elastography. Invest Radiol 46(8):509-514. doi:10.1097/RLI.0b013e3182183a95

15. Goertz RS, Egger C, Neurath MF, Strobel D (2012) Impact of food intake, ultrasound transducer, breathing maneuvers and body position on acoustic radiation force impulse (ARFI) elastometry of the liver. Ultraschall Med 33(4):380-385

16. Nedredal GI, Yin M, McKenzie T et al (2011) Portal hypertension correlates with splenic stiffness as measured with MR elastography. J Magn Reson Imaging 34(1):79-87. doi:10.1002/jmri.22610

17. Ye XP, Ran HT, Cheng J et al (2012) Liver and spleen stiffness measured by acoustic radiation force impulse elastography for noninvasive assessment of liver fibrosis and esophageal varices in patients with chronic hepatitis B. J Ultrasound Med 31(8):1245-1253

18. Gao J, Ran HT, Ye XP, Zheng YY, Zhang DZ, Wang ZG (2012) The stiffness of the liver and spleen on ARFI imaging pre and post TIPS placement: a preliminary observation. Clin Imaging 36(2):135141. doi:10.1016/j.clinimag.2011.11.014

19. Furuichi Y, Moriyasu F, Taira J et al (2013) Noninvasive diagnostic method for idiopatic portal hypertension based on measurements of liver and spleen stiffness by ARFI elastography. J Gastroenterol 48(9):1061-1068. doi:10.1007/s00535-012-0703-Z

20. Fahey BJ, Nightingale KR, Nelson RC, Palmeri ML, Trahey GE (2005) Acoustic radiation force impulse imaging of the abdomen: demonstration of feasibility and utility. Ultrasound Med Biol 31(9): $1185-1198$

21. Goertz RS, Amann K, Heide R, Bernatik T, Neurath MF, Strobel D (2011) An abdominal and thyroid status with Acoustic Radiation Force Impulse Elastometry - a feasibility study: Acoustic Radiation Force Impulse Elastometry of human organs. Eur J Radiol 80(3): e226-e230. doi:10.1016/j.ejrad.2010.09.025

22. D'Anastasi M, Schneevoigt BS, Trottmann M et al (2011) Acoustic radiation force impulse imaging of the testes: a preliminary experience. Clin Hemorheol Microcirc 49(1-4):105114. doi:10.3233/CH-2011-1461

23. Syversveen T, Brabrand K, Midtvedt K et al (2011) Assessment of renal allograft fibrosis by acoustic radiation force impulse quantification - a pilot study. Transpl Int 24(1):100-105. doi:10.1111/j.14322277.2010.01165.x

24. Stock KF, Klein BS, Cong MT et al (2011) ARFI-based tissue elasticity quantification and kidney graft dysfunction: first clinical experiences. Clin Hemorheol Microcirc 49(1-4):527-535. doi:10.3233/CH-2011-1503

25. Bruno C, Caliari G, Zaffanello M et al (2013) Acoustic radiation force impulse (ARFI) in the evaluation of the renal parenchymal stiffness in paediatric patients with vesicoureteral reflux: preliminary results. Eur Radiol 23(12):3477-3484. doi:10.1007/s00330-013-2959-y

26. Bob F, Bota S, Sporea I, Șirli R, Petrica L, Schiller A (2014) Kidney shear wave speed values in subjects with and without renal pathology and inter-operator reproducibility of acoustic radiation force impulse elastography (ARFI) - preliminary results. PLoS ONE 9(11):e113761. doi:10.1371/journal. pone. 0113761

27. Tublin ME, Dodd GD III (1995) Sonography of renal transplantation. Radiol Clin North Am 33(3):447-459

28. Strader DB, Wright T, Thomas DL, Seeff LB (2004) Diagnosis, management, and treatment of hepatitis C. Hepatology 39(4):1147-1171

29. Kobayashi K, Nakao H, Nishiyama T et al (2015) Diagnostic accuracy of real-time tissue elastography for the staging of liver fibrosis: a metaanalysis. Eur Radiol 25(1):230-238. doi:10.1007/s00330-014-3364-x 
30. Sporea I, Gilja OH, Bota S, Şirli R, Popescu A (2013) Liver elastography - an update. Med Ultrason 15(4):304-314

31. Yano M, Kumada H, Kage M et al (1996) The long-term pathological evolution of chronic hepatitis C. Hepatology 23(6):1334-1340

32. Bravo AA, Sheth SG, Chopra S (2001) Liver biopsy. N Engl J Med 344(7):495-500

33. Friedrich-Rust M, Ong MF, Martens S et al (2008) Performance of transient elastography for the staging of liver fibrosis: a meta-analysis. Gastroenterology 134(4):960-974. doi:10.1053/j.gastro.2008.01.034

34. Shaheen AA, Wan AF, Myers RP (2007) FibroTest and FibroScan for the prediction of hepatitis C-related fibrosis: a systematic review of diagnostic test accuracy. Am J Gastroenterol 102(11):2589-2600

35. Tsochatzis EA, Gurusamy KS, Ntaoula S, Cholongitas E, Davidson BR, Burroughs AK (2011) Elastography for the diagnosis of severity of fibrosis in chronic liver disease: a meta-analysis of diagnostic accuracy. J Hepatol 54(4):650-659. doi:10.1016/j.jhep.2010.07.033

36. Wang J, Guo L, Shi X, Pan W, Bai Y, Ai H (2012) Real-time elastography with a novel quantitative technology for assessment of liver fibrosis in chronic hepatitis B. Eur J Radiol 81(1):e31-e36. doi:10.1016/j.ejrad.2010.12.013

37. Friedrich-Rust M, Nierhoff J, Lupsor M et al (2012) Performance of acoustic radiation force impulse imaging for the staging of liver fibrosis: a pooled meta-analysis. J Viral Hepat 19(2):e212-e219. doi:10.1111/j.1365-2893.2011.01537.x

38. Bota S, Herkner H, Sporea I et al (2013) Meta-analysis: ARFI elastography versus transient elastography for the evaluation of liver fibrosis. Liver Int 33(8):1138-1147. doi:10.1111/liv.12240

39. Sporea I, Bota S, Peck-Radosavljevic M et al (2012) Acoustic radiation force impulse elastography for fibrosis evaluation in patients with chronic hepatitis C: an international multicenter study. Eur J Radiol 81(12):4112-4118. doi:10.1016/j.ejrad.2012.08.018

40. Rizzo L, Calvaruso V, Cacopardo B et al (2011) Comparison of transient elastography and acoustic radiation force impulse for noninvasive staging of liver fibrosis in patients with chronic hepatitis C. Am J Gastroenterol 106(12):2112-2120. doi:10.1038/ajg.2011.341

41. Friedrich-Rust M, Wunder K, Kriener S et al (2009) Liver fibrosis in viral hepatitis: noninvasive assessment with acoustic radiation force impulse imaging versus transient elastography. Radiology 252(2):595-604. doi:10.1148/radiol.2523081928

42. Sporea I, Sirli R, Deleanu A et al (2011) Acoustic radiation force impulse elastography as compared to transient elastography and liver biopsy in patients with chronic hepatopathies. Ultraschall Med 32(Suppl 1):S46-S52. doi:10.1055/s-0029-1245360

43. Cassinotto C, Lapuyade B, Ait-Ali A et al (2013) Liver fibrosis: noninvasive assessment with acoustic radiation force impulse elastography-comparison with FibroScan M and XL probes and FibroTest in patients with chronic liver disease. Radiology 269(1): 283-292. doi:10.1148/radiol.13122208

44. Zhang D, Li P, Chen M et al (2015) Non-invasive assessment of liver fibrosis in patients with alcoholic liver disease using acoustic radiation force impulse elastography. Abdom Imaging 40(4):723729. doi:10.1007/s00261-014-0154-5

45. Hu Z, Luo J, Wei H et al (2015) Correlation of virtual touch tissue quantification and liver biopsy in a rat liver fibrosis model. Mol Med Rep 11(5):3694-3700. doi:10.3892/mmr.2015.3209

46. Jaffer OS, Lung PF, Bosanac D et al (2012) Acoustic radiation force impulse quantification: repeatability of measurements in selected liver segments and influence of age, body mass index and liver capsule-to-box distance. Br J Radiol 85(1018):e858-e863. doi:10.1259/bjr/74797353

47. Piscaglia F, Salvatore V, Di Donato R et al (2011) Accuracy of VirtualTouch acoustic radiation force impulse (ARFI) imaging for the diagnosis of cirrhosis during liver ultrasonography. Ultraschall Med 32(2):167-175. doi:10.1055/s-0029-1245948

48. Nierhoff J, Chávez Ortiz AA, Hermann E, Zeuzem S, FriedrichRust M (2013) The efficiency of acoustic radiation force impulse imaging for the staging of liver fibrosis: a meta-analysis. Eur Radiol 23(11):3040-3053. doi:10.1007/s00330-013-2927-6

49. Bota S, Sporea I, Şirli R et al (2014) Factors associated with the impossibility to obtain reliable liver stiffness measurements by means of acoustic radiation force impulse (ARFI) elastographyanalysis of a cohort of 1,031 subjects. Eur J Radiol 83(2):268 272. doi:10.1016/j.ejrad.2013.11.019

50. Liao LY, Kuo KL, Chiang HS, Lin CZ, Lin YP, Lin CL (2015) Acoustic radiation force impulse elastography of the liver in healthy patients: test location, reference range and influence of gender and body mass index. Ultrasound Med Biol 41(3):698-704. doi:10.1016/j.ultrasmedbio.2014.09.030

51. Nishikawa T, Hashimoto S, Kawabe $\mathrm{N}$ et al (2014) Factors correlating with acoustic radiation force impulse elastography in chronic hepatitis C. World J Gastroenterol 20(5):1289-1297. doi:10.3748/wjg.v20. i5.1289

52. Fontanilla T, Cañas T, Macia A et al (2014) Normal values of liver shear wave velocity in healthy children assessed by acoustic radiation force impulse imaging using a convex probe and a linear probe. Ultrasound Med Biol 40(3):470-477. doi:10.1016/j.ultrasmedbio.2013

53. Yoon KT, Lim SM, Park JY et al (2012) Liver stiffness measurement using acoustic radiation force impulse (ARFI) elastography and effect of necroinflammation. Dig Dis Sci 57(6):1682-1691. doi:10.1007/s10620-012-2044-4

54. Bota S, Sporea I, Peck-Radosavljevic M et al (2013) The influence of aminotransferase levels on liver stiffness assessed by acoustic radiation force impulse elastography: a retrospective multicentre study. Dig Liver Dis 45(9):762-768. doi:10.1016/j.dld.2013.02.008

55. Yoshioka K, Hashimoto S, Kawabe N (2015) Measurement of liver stiffness as a non-invasive method for diagnosis of non-alcoholic fatty liver disease. Hepatol Res 45(2):142-151. doi:10.1111/hepr.12388

56. Park MS, Kim SW, Yoon KT et al (2016) Factors influencing the diagnostic accuracy of acoustic radiation force impulse elastography in patients with chronic hepatitis B. Gut Liver 10(2): 275-282. doi:10.5009/gnl14391

57. Sporea I, Bota S, Şirli R et al (2012) Acoustic radiation force impulse (ARFI) elastography for the assessment of liver fibrosis in patients with chronic hepatitis $\mathrm{B}$ and $\mathrm{C}$ - an international multicenter study. J Hepatol 56(suppl 2):S421-S422

58. Tai DI, Tsay PK, Jeng WJ et al (2015) Differences in liver fibrosis between patients with chronic hepatitis B and C: evaluation by acoustic radiation force impulse measurements at 2 locations. J Ultrasound Med 34(5):813-821. doi:10.7863/ultra.34.5.813

59. Hanquinet S, Courvoisier DS, Rougemont AL et al (2015) Contribution of acoustic radiation force impulse (ARFI) elastography to the ultrasound diagnosis of biliary atresia. Pediatr Radiol 45(10):1489-1495. doi:10.1007/s00247-015-3352-6

60. Efe C, Gungoren MS, Ozaslan E, Akbiyik F, Kav T (2015) Acoustic radiation force impulse (ARFI) for fibrosis staging in patients with autoimmune hepatitis. Hepatogastroenterology 62(139):670-672

61. Zhang DK, Chen M, Liu Y, Wang R, Liu LP, Li M (2014) Acoustic radiation force impulse elastography for non-invasive assessment of disease stage in patients with primary biliary cirrhosis: A preliminary study. Clin Radiol 69(8):836-840. doi:10.1016/j.crad.2014.03.019

62. Liu H, Fu J, Hong R, Liu L, Li F (2015) Acoustic radiation force impulse elastography for the non-invasive evaluation of hepatic fibrosis in non-alcoholic fatty liver disease patients: a systematic review \& meta-analysis. PLoS One 10(7):e0127782. doi:10.1371/journal. pone. 0127782

63. Bignulin S, Falleti E, Cmet S et al (2016) Usefulness of acoustic radiation force impulse and fibrotest in liver fibrosis assessment after liver transplant. Ann Hepatol 15(2):200-206. doi: $10.5604 / 16652681.1193710$

64. De Franchis R (2010) Revising consensus in portal hypertension: report of the Baveno $\mathrm{V}$ consensus workshop on methodology of 
diagnosis and therapy in portal hypertension. J Hepatol 53:762768. doi:10.1016/j.jhep.2010.06.004

65. Salzl P, Reiberger T, Homoncik M et al (2010) Comparison of liver stiffness assessment by Fibroscan and acoustic radiation force impulse imaging for the evaluation of liver fibrosis and cirrhosis. $\mathrm{J}$ Hepatol 52(suppl 1):S171

66. Park Y, Kim SU, Park SY et al (2015) A novel model to predict esophageal varices in patients with compensated cirrhosis using Acoustic Radiation Force Impulse elastography. PLoS One 10(3): e0121009. doi:10.1371/journal.pone.0121009

67. Lim R (2009) Vesicoureteral reflux and urinary tract infection: evolving practices and current controversies in pediatric imaging. AJR Am J Roentgenol 192(5):1197-1208. doi:10.2214/AJR.08.2187

68. Brader P, Riccabona M, Schwarz T, Seebacher U, Ring E (2008) Value of comprehensive renal ultrasound in children with acute urinary tract infection for assessment of renal involvement: comparison with DMSA scintigraphy and final diagnosis. Eur Radiol 18(12):2981-2989. doi:10.1007/s00330-008-1081-z

69. Riccabona M, Avni FE, Blickman JG et al (2009) Imaging recommendations in paediatric uroradiology: minutes of the ESPR uroradiology task force session on childhood obstructive uropathy, high-grade fetal hydronephrosis, childhood hematuria, and urolithiasis in childhood. ESPR Annual Congress, Edinburgh, UK, June 2008. Pediatr Radiol 39(8):891-898. doi:10.1007/s00247-009-1233-6

70. Arndt R, Schmidt S, Loddenkemper C et al (2010) Noninvasive evaluation of renal allograft fibrosis by transient elastography - a pilot study. Transpl Int 23(9):871-877. doi:10.1111/j.14322277.2010.01057.x

71. Grenier N, Poulain S, Lepreux S et al (2012) Quantitative elastography of renal transplants using supersonic shear imaging: a pilot study. Eur Radiol 22(10):2138-2146. doi:10.1007/s00330-012-2471-9

72. He WY, Jin YJ, Wang WP, Li CL, Ji ZB, Yang C (2014) Tissue elasticity quantification by acoustic radiation force impulse for the assessment of renal allograft function. Ultrasound Med Biol 40(2): 322-329. doi:10.1016/j.ultrasmedbio.2013.10.003

73. Lee J, Oh YT, Joo DJ et al (2015) Acoustic radiation force impulse measurement in renal transplantation. A prospective, longitudinal study with protocol biopsies. Medicine (Baltimore) 94(39):e1590. doi:10.1097/MD.0000000000001590

74. Brenner BM, Meyer TW, Hostetter TH (1982) Dietary protein intake and the progressive nature of kidney disease: the role of hemodynamically mediated glomerular injury in the pathogenesis of progressive glomerular sclerosis in aging, renal ablation, and intrinsic renal disease. N Engl J Med 307(11):652-659

75. Wang L, Xia P, Lv K et al (2014) Assessment of renal tissue elasticity by acoustic radiation force impulse quantification with histopathological correlation: preliminary experience in chronic kidney disease. Eur Radiol 24(7):1694-1699. doi:10.1007/s00330-014-3162-5
76. Cui G, Yang Z, Zhang W et al (2014) Evaluation of acoustic radiation force impulse imaging for the clinicopathological typing of renal fibrosis. Exp Ther Med 7(1):233-235. doi:10.3892/etm.2013.1377

77. Bob F, Bota S, Sporea I, Şirli R, Popescu A, Schiller A (2015) Relationship between the estimated glomerular filtration rate and kidney shear wave speed values assessed by acoustic radiation force impulse elastography: a pilot study. J Ultrasound Med 34(4):649654. doi:10.7863/ultra.34.4.649

78. Asano K, Ogata A, Tanaka K et al (2014) Acoustic radiation force impulse elastography of the kidneys: is shear wave velocity affected by tissue fibrosis or renal blood flow? J Ultrasound Med 33(5):793801. doi:10.7863/ultra.33.5.793

79. Sohn B, Kim MJ, Han SW, Im YJ, Lee MJ (2014) Shear wave velocity measurements using acoustic radiation force impulse in young children with normal kidneys versus hydronephrotic kidneys. Ultrasonography 33(2):116-121. doi:10.14366/usg.14002

80. Mateen MA, Muheet KA, Mohan RJ et al (2012) Evaluation of ultrasound-based acoustic radiation force impulse (ARFI) and eSie-touch sonoelastography for diagnosis of inflammatory pancreatic diseases. J Pancreas (Online) 13(1):36-44

81. Göya C, Hamidi C, Hattapoğlu S et al (2014) Use of acoustic radiation force impulse elastography to diagnose acute pancreatitis at hospital admission. Comparison with sonography and computed tomography. J Ultrasound Med 33(8):1453-1460. doi:10.7863/ultra.33.8.1453

82. Yashima Y, Sasahira N, Isayama $H$ et al (2012) Acoustic radiation force impulse elastography for noninvasive assessment of chronic pancreatitis. J Gastroenterol 47(4):427-432. doi:10.1007/s00535-011-0491-x

83. Friedrich-Rust M, Schlueter N, Smaczny C et al (2013) Noninvasive measurement of liver and pancreas fibrosis in patients with cystic fibrosis. J Cyst Fibros 12(5):431-439. doi:10.1016/j. jcf.2012.12.013

84. Harada N, Ishizawa T, Inoue $Y$ et al (2014) Acoustic radiation force impulse imaging of the pancreas for estimation of pathologic fibrosis and risk of postoperative pancreatic fistula. J Am Coll Surg 219(5):887-894. doi:10.1016/j.jamcollsurg.2014.07.940

85. Fukuhara T, Matsuda E, Endo Y, et al. (2015) Impact of fibrotic tissue on shear wave velocity in thyroid: an ex vivo study with fresh thyroid specimens. Biomed Res Int: 569367. doi: 10.1155/2015 1569367

86. Hekimoglu K, Yildirim Donmez F, Arslan S, Ozdemir A, Demir C, Yazici C (2015) The role of shear wave elastography in the diagnosis of chronic autoimmune thyroiditis. Med Ultrason 17(3):322326. doi:10.11152/mu.2013.2066.173.khu

87. Sporea I, Șirli R, Bota S, Vlad M, Popescu A, Zosin I (2012) ARFI elastography for the evaluation of diffuse thyroid gland pathology: Preliminary results. World J Radiol 4(4):174-178. doi:10.4329/wjr. v4.i4.174 